\title{
pH-Responsive Vesicle Formation by PEGylated Cholesterol Derivatives: \\ Physicochemical Characterization, Stability, Encapsulation and Release Study
}

\section{Supporting Information}

\section{Synthetic Procedure}

The amphiphiles Chol-Cys-PEG4 and Chol-Cys-PEG23 were first synthesized by reacting cholesteryl chloroformate with mPEG4-Cys (or $\mathrm{mPEG}_{23}-\mathrm{Cys}$ ), which were obtained by the nucleophilic addition reaction of $\mathrm{mPEG}_{4}$ (or $\mathrm{mPEG}_{23}$ ) with L-Cysteine using thiol-ene click chemistry according to a procedure already reported by us. [1] In a 100-mL (single-neck) RB flask fitted with a magnetic stirrer, $\mathrm{mPEG}_{4}-\mathrm{Cys}(1.0 \mathrm{eq})$ or $\mathrm{mPEG}_{23}-\mathrm{Cys}(1.0 \mathrm{eq})$ was dissolved in super dry THF containing 1 eq. super dry Et ${ }_{3} \mathrm{~N}$. But it remains insoluble in THF even after $1 \mathrm{~h}$ of stirring. Then some amount of super dry $\mathrm{MeOH}$ was added to the RB to dissolve the whole mixture. The reaction mixture was further stirred at R.T. for $30 \mathrm{~min}$. The solution was cooled to 0 ${ }^{\circ} \mathrm{C}$ in an ice-bath. To this cold solution, cholesteryl chloroformate $(0.9$ eq.) dissolved in dry THF was added drop wise with continuous stirring over a period of $2 \mathrm{~h}$. The $\mathrm{pH}$ of the reaction mixture was maintained at $8-9$ by addition of $\mathrm{Et}_{3} \mathrm{~N}$ at regular intervals. After stirring for $20 \mathrm{~h}$, the solvent was evaporated in a rotavapor, and the residual milky white slurry was transferred into a 50-mL beaker by use of a minimum volume $(\sim 10 \mathrm{~mL})$ of distilled water was added to mobilize the mass. The resulting aqueous milky white dispersion was acidified with aqueous dilute $\mathrm{HCl}(0.5 \mathrm{M})$ to $\mathrm{pH} \sim 2$. The acidified aqueous solution was then extracted by $\mathrm{CHCl}_{3}$ repeatedly to get the pure product. All the $\mathrm{CHCl}_{3}$ fractions were collected and then the solvent was evaporated out. The product was dried in desiccators overnight under reduced pressure to get a colorless viscous liquid or semi- 
solid. The overall synthetic scheme has been exhibited in Figure S1. The product (acid form) was characterized by FT-IR, ${ }^{1} \mathrm{H}-\mathrm{NMR}$, and ${ }^{13} \mathrm{C}-\mathrm{NMR}$ spectra. Representative ${ }^{1} \mathrm{H}-\mathrm{NMR}$ and ${ }^{13} \mathrm{C}$ NMR spectra of the acid form of Chol-Cys-PEG 4 are presented in Figure S1 and Figure S2, respectively. As the structures of the amphiphiles are identical, (except the PEG chain length) the spectral data are given below only for Chol-Cys- $\mathrm{PEG}_{4}$ as a representative molecule.

For the preparation of sodium salt, $\mathrm{NaHCO}_{3}$ (1.2 eq.) dissolved in distilled water was added drop wise to a solution of Chol-Cys-PEG 4 (1 eq.) or Chol-Cys-PEG 23 (1 eq) dissolved in THF over a period of 15 min with continuous stirring at room temperature. The mixture immediately turned turbid, but became clear during the course of the reaction. After stirring for $12 \mathrm{~h}$, THF was evaporated, leaving a colorless slurry in the RB flask. The mass was freeze-dried to remove the water and the pure salt (NaChol-Cys-PEG 4 or NaChol-Cys- $\left.-\mathrm{PEG}_{23}\right)$ was then extracted with $\mathrm{CHCl}_{3}$ as $\mathrm{NaHCO}_{3}$ is insoluble in $\mathrm{CHCl}_{3}$. Evaporation of the solvent in a rotavapor gave the desired pure product in $\sim 80 \%$ yield. 


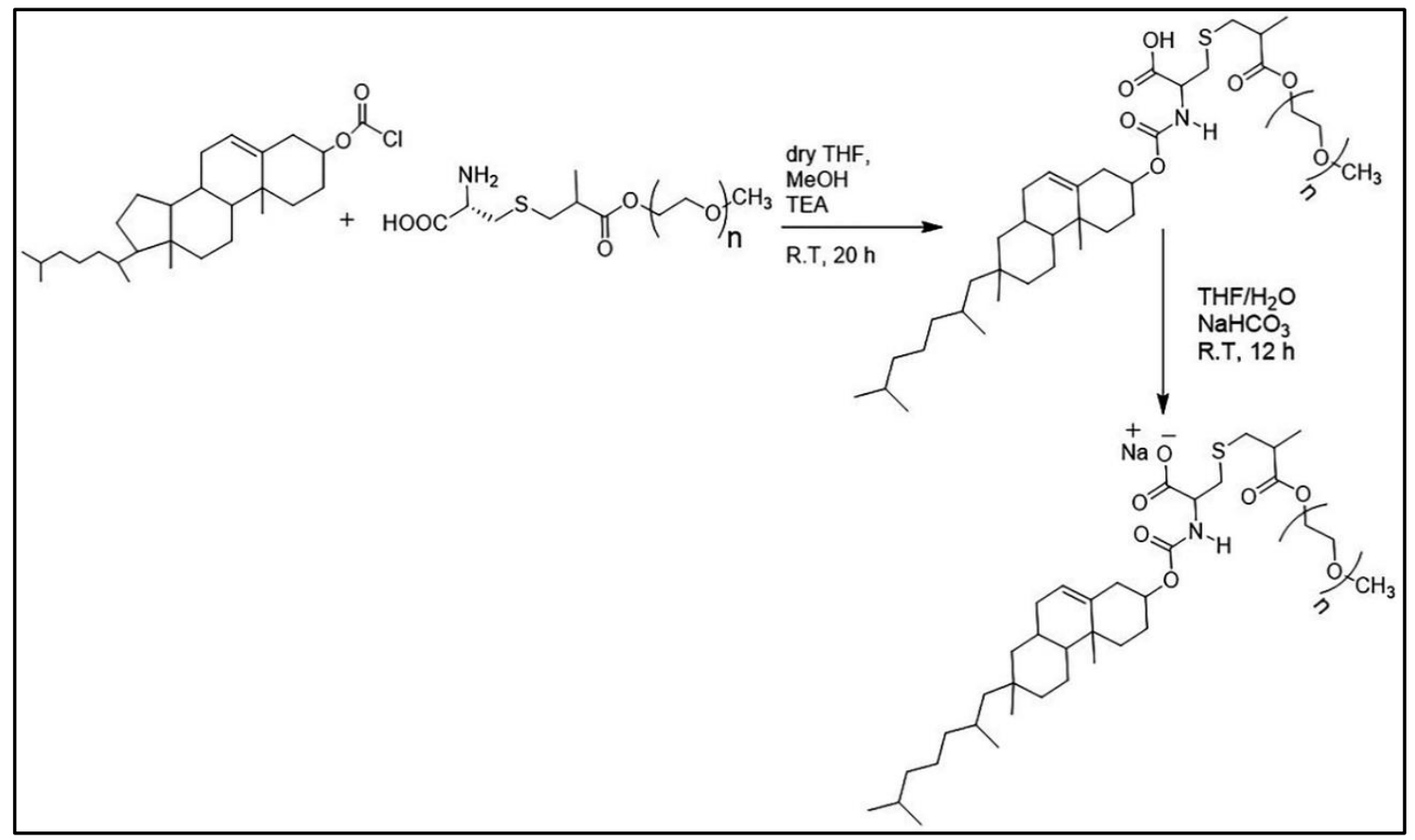

Scheme S1 General synthetic scheme for NaChol-Cys-PEG4 or NaChol-Cys-PEG23 amphiphiles.

Chemical Identification. MW: 833.8 (Chol-Cys-PEG 4 ) and 1655.8 (Chol-Cys-PEG 23 ), State: viscous liquid, Yield: 80-85\%, FTIR (KBr, $\mathbf{c m}^{-\mathbf{1}}$ ): 3501 (broad, carboxylic acid O-H stretch), 3423 (strong, N-H stretch), 2945 (sp2 C-H stretch), 2901 and 2862 (sp3 C-H stretch), 1728 (carboxylic acid $\mathrm{C}=\mathrm{O}$ stretch), $1695(\mathrm{NH}(\mathrm{C}=\mathrm{O}) \mathrm{O}$ stretch), $1519(\mathrm{~N}-\mathrm{H}$ bend), 1256, 1218, 1076, and 1038 (C-O stretches); ${ }^{\mathbf{1}} \mathbf{H}-\mathbf{N M R}$ (CDCl3, 400 MHz): $\delta$ (ppm) 5.377 (olefinic $\boldsymbol{H}$ cholestanyl, d, 1H), $5.170(\mathrm{NHCOO}, \mathrm{d}, 1 \mathrm{H}), 4.516$ (cholestanyl $\mathrm{CHO}(\mathrm{CO}), \mathrm{s}, 1 \mathrm{H}), 4.388\left(\mathrm{CH}_{3} \mathrm{CHCOOH}, \mathrm{t}\right.$, 1H), 2.312 (cholestanyl $\mathrm{CH}_{2}, \mathrm{~d}, 2 \mathrm{H}$ ), 1.014 (cholestanyl $\mathrm{CH}_{3}, \mathrm{~s}, 3 \mathrm{H}$ ), 0.916 (cholestanyl $\mathrm{CH}_{3}, \mathrm{~d}$, 3H), 0.869 (cholestanyl $\left.\mathrm{CH}\left(\mathrm{CH}_{3}\right)_{2}, \mathrm{~d}, 6 \mathrm{H}\right), 0.680$ (cholestanyl $\left.\mathrm{CH}_{3}, \mathrm{~s}, 3 \mathrm{H}\right), 1.254$ (COCHCH , t, 3H), 2.868 (COOHCHCH 2, d, 2H), 3.043 ( $\left.\mathrm{SCH}_{2}-\mathrm{CH}, \mathrm{d}, 2 \mathrm{H}\right), 3.203\left(\mathrm{SCH}_{2} \mathrm{CHCO}, \mathrm{m}, 1 \mathrm{H}\right), 3.381$ $\left(\mathrm{OCH}_{3}, \mathrm{~s}, 3 \mathrm{H}\right), 3.558\left(\mathrm{CO}-\mathrm{OCH}_{2} \mathrm{CH}_{2}, \mathrm{t}, 2 \mathrm{H}\right), 3.661$ (long chain glycolic $\mathrm{CH}_{2}, \mathrm{~m}, 18 \mathrm{H}$ for CPCF3 
and $108 \mathrm{H}$ for CPCF11), $3.729\left(\mathrm{OCH}_{3} \mathrm{CH}_{2} \mathrm{CH}_{2}, \mathrm{t}, 2 \mathrm{H}\right), 3.795\left(\mathrm{NH}_{2} \mathrm{CHCH}_{2}, \mathrm{t}, 1 \mathrm{H}\right), 4.351(\mathrm{CO}-$ $\left.\mathrm{OCH}_{2}-\mathrm{CH}_{2}, \mathrm{dd}, 2 \mathrm{H}\right) ;{ }^{13} \mathbf{C}-\mathrm{NMR}(\mathbf{C D C l 3}, 400 \mathrm{MHz}): \delta(\mathrm{ppm}) 174.78(\boldsymbol{C O O C H} 2), 171.95$ $(\boldsymbol{C O O H}), 155.49(\mathrm{NHCOO}), 139.51(-\boldsymbol{C}=\mathrm{CH}), 122.52(-\mathrm{C}=\boldsymbol{C H}), 49.90(\boldsymbol{C H}), 68.7,67.3$, 66.1, 61.5 (ether $\left.\boldsymbol{C H}_{2}\right), 55.7\left(\mathrm{OCH}_{3}\right), 51.4\left(\mathrm{NCH}^{2} \mathrm{CH}_{2}\right) 37.7\left(\mathrm{SCH}_{2} \mathrm{CH}\right), 32.2\left(\mathrm{SCH}_{2} \mathrm{CH}\right), 30.3$ $\left(\mathrm{SCH}_{2} \mathrm{CH}_{2} \mathrm{NH}_{2}\right), 29\left(\mathrm{CH}_{2} \mathrm{CH}_{2} \mathrm{CH}_{2} \mathrm{CH}_{2}\right), 13.9\left(\mathrm{CH}_{3}\right)$.

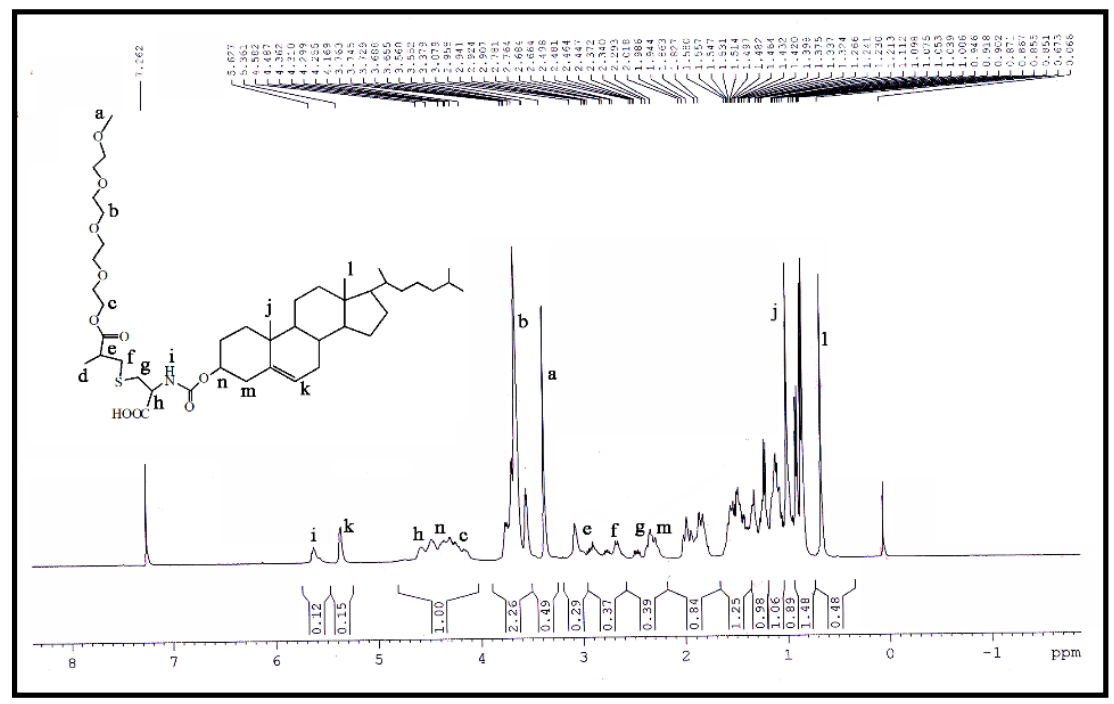

Figure S1 ${ }^{1} \mathrm{H}-\mathrm{NMR}$ spectrum of Chol-Cys-PEG 4 in $\mathrm{CDCl}_{3}$. 


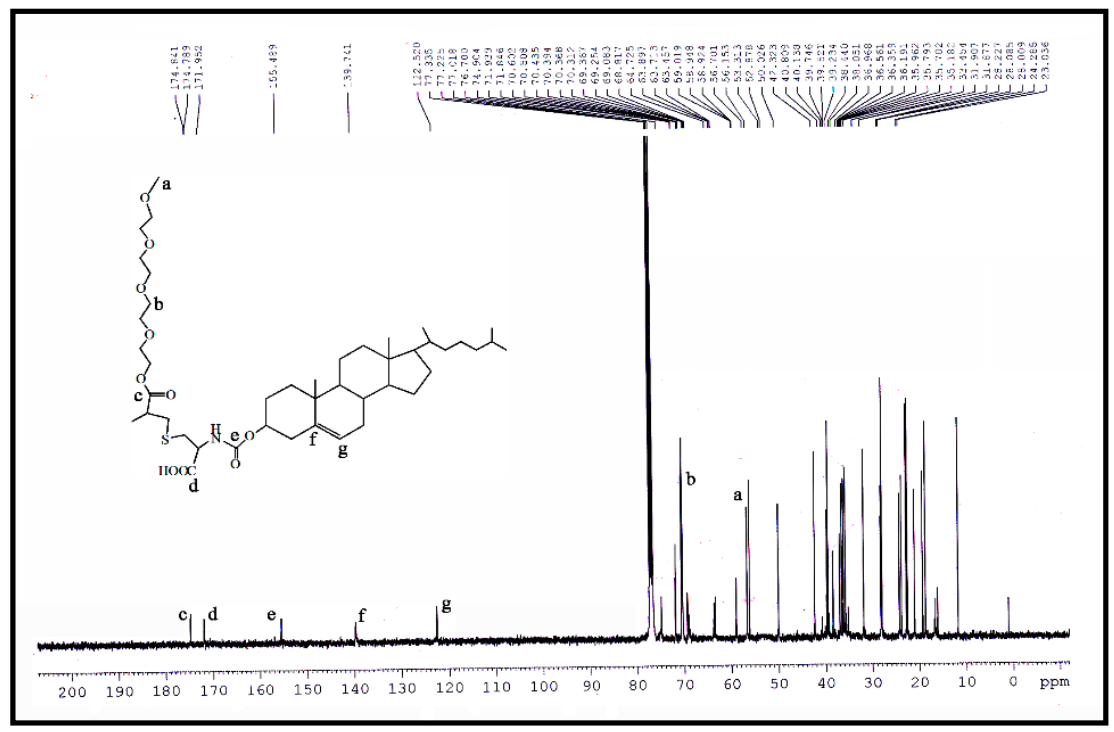

Figure S2 ${ }^{13} \mathrm{C}-\mathrm{NMR}$ spectrum of Chol-Cys-PEG 4 in $\mathrm{CDCl}_{3}$.

\section{Experimental methods}

\subsection{Surface tension measurements}

Surfacetension $(\gamma)$ measurements were performed on a GBX 3S (France) surface tensiometer using Du Näy ring method. The instrument was calibrated and checked by measuring the surface tension of Milli-Q water $(18 \mathrm{M} \Omega \mathrm{cm})$ before each experiment. To a $10 \mathrm{~mL}$ phosphate buffer $(20 \mathrm{mM}, \mathrm{pH} 7.0, \mathrm{I}=0.1)$ solution, aliquots were added in measuredrolumeand $\gamma$ $(\mathrm{mN} \mathrm{m}-1)$ valuewas measuredin each case. The solution was gently stirred and allowed to equilibrate for $10 \mathrm{~min}$ before each measurement. Each measurement was repeated at least three times to check reproducibilityof the measuredvalueof $\gamma$. The temperature of the solution was controlled by a JULABO MC water-circulating bath with a temperature accuracy of $\pm 0.1^{\circ} \mathrm{C}$.

\subsection{Steady-state fluorescence measurements}


The steady-state fluorescence measurements involving NPN and DPH were carried out on a Perkin Elmer LS-55 luminescence spectrometer equipped with a temperature-controlled cell holder or on a Horiba FL3-11 spectrophotometer (Japan). A SPEX Fluorolog-3 (model FL3-11, USA) spectrophotometer was used for recording fluorescence emission spectra of Py. Py solutions were excited at $335 \mathrm{~nm}$, and emission spectra were recorded in the wavelength range of 350-500 nm using excitation and emission slit widths of 3 and $1 \mathrm{~nm}$, respectively. The solutions containing NPN were excited at $340 \mathrm{~nm}$, and the emission was followed between 350 and 600 $\mathrm{nm}$. The slit width was set at $2.5 \mathrm{~nm}$ for excitation and $2.5-10 \mathrm{~nm}$ for the emission, depending upon sample concentration. Temperature-controlled measurements were carried out by use of a Thermo Neslab RTE-7 water-circulating bath with a temperature accuracy of $\pm 0.1{ }^{\circ} \mathrm{C}$.

\subsection{Fluorescence anisotropy measurements.}

A PerkinElmer LS-55 luminescence spectrometer was used to measure the steadystate fluorescence anisotropy $(r)$ of DPH in presence of the surfactants. The instrument is equipped with a polarization accessory that uses the L-format instrumental configuration and a thermostating and magnetically stirred cell housing that allowed temperature control. The anisotropy was calculated employing the equation:

$$
r=\left(I_{V V}-\mathrm{G} I_{V H}\right) /\left(I_{V V}+2 \mathrm{G} I_{V H}\right)
$$

where $I_{V V}$ and $I_{V H}$ are the fluorescence intensities polarized parallel and perpendicular to the excitation light, and $\mathrm{G}\left(=I_{H V} / I_{H H}\right)$ is the instrumental grating factor.[2-4] The software supplied by the manufacturer automatically determined the G factor and $r$. The sample was excited at 350 $\mathrm{nm}$ and the emission intensity was followed at $450 \mathrm{~nm}$ using excitation and emission slits width of 2.5 
$\mathrm{nm}$ and $2.5-10.0 \mathrm{~nm}$, respectively. A $430 \mathrm{~nm}$ cut-off filter was placed in the emission beam to eliminate the effect of scattered radiation. All measurements started $30 \mathrm{~min}$ after sample preparation. Before measurement started, each solution was equilibrated for 10 minutes at the desired temperature. For each measurement, the $r$ value was recorded over an integration time of $10 \mathrm{~s}$. For each sample, an average of five readings was accepted as the value of $r$.

\subsection{Time-resolved fluorescence measurements.}

Optical Building Blocks Corporation Easylife instrument was employed to measure the fluorescence lifetime of DPH probe. The light source was a $380 \mathrm{~nm}$ diode laser. The timeresolved decay curves were analyzed by single exponential or bi-exponential iterative fitting program. The best fit was judged by the $\chi^{2}$ value $(0.8-1.2)$ and by the randomness of the residual plot.

\subsection{Determination of microviscosity.}

The rigidity or fluidity of the microenvironment of the self-assemblies was measured by determination of the microviscosity $\left(\eta_{\mathrm{m}}\right)$ using DPH probe [3]. The $\eta_{\mathrm{m}}$ was calculated from the values of $r$ and rotational correlation time $\left(\tau_{\mathrm{R}}\right)$ of DPH probe using Debye-Stokes-Einstein relation:

$$
\eta_{\mathrm{m}}=k \mathrm{~T} \tau_{\mathrm{R}} / \nu_{\mathrm{h}}
$$

where $v_{\mathrm{h}}$ is the hydrodynamic volume $\left(313 \AA^{3}\right)$ [5] of the DPH molecule. The $\tau_{\mathrm{R}}$ was calculated using Perrin's equation:

$$
\tau_{\mathrm{R}}=\tau_{\mathrm{f}}\left(r_{\mathrm{o}} / r-1\right)^{-1}
$$

where $r_{\mathrm{o}}(=0.362)[3,4]$ and $\tau_{\mathrm{f}}$ are the steady-state fluorescence anisotropy of DPH in a highly viscous solvent and measured fluorescence lifetime of DPH in surfactant solution, respectively. 


\subsection{Dynamic light scattering.}

The dynamic light scattering (DLS) measurements were performed with a Zetasizer Nano ZS (Malvern Instrument Lab, Malvern, U.K.) light scattering spectrometer equipped with a He-Ne laser operated at $4 \mathrm{~mW}\left(\lambda_{0}=632.8 \mathrm{~nm}\right)$ at $25{ }^{\circ} \mathrm{C}$. The solution was filtered directly into the thoroughly cleaned scattering cell through a Millipore Millex syringe filter (Triton free, $0.22 \mu \mathrm{m}$ ). The sample was allowed to equilibrate inside the DLS optical system chamber for $10 \mathrm{~min}$ prior to the start of measurement. The back scattering intensity was measured at $\theta=173^{\circ}$ to the incident beam. The data acquisition was carried out for at least 15 counts and each experiment was repeated thrice.

\subsection{Zeta potential measurements.}

The surface zeta $(\zeta)$ potential of the aggregates were also measured using the same Zetasizer Nano ZS (Malvern Instrument Laboratory, Malvern, U.K.) optical system equipped with a He-Ne laser operated at $4 \mathrm{~mW}\left(\lambda_{0}=632.8 \mathrm{~nm}\right)$ at $25^{\circ} \mathrm{C}$. The measurements were done by taking different surfactant concentrations at $25{ }^{\circ} \mathrm{C}$ in $\mathrm{pH} 7.0$ at $25{ }^{\circ} \mathrm{C}$. An average of three successive measurements was noted for each sample.

\subsection{Transmission electron microscopy (TEM).}

The morphology of the aggregates was investigated by a high resolution transmission electron microscope (JEM - 2100 HRTEM, Make - JEOL, Japan) operating at an accelerating voltage of $200 \mathrm{kV}$. A $4 \mu \mathrm{L}$ volume of surfactant solution was dropped on to a 400 mesh carboncoated copper grid, and allowed to stand for $1 \mathrm{~min}$. The excess solution was blotted with a piece of tissue paper, and the grid was air-dried. The specimens were kept in desiccators overnight before measurement. Each measurement was repeated at least thrice to check the reproducibility. 


\subsection{Isothermal titration calorimetry (ITC)}

An isothermal titration, Microcal $\mathrm{iTC}_{200}$, (U.S.A) was used for thermometric measurements. In a microsyringe of capacity $40 \mu \mathrm{L}$, concentrated solution $(0.1 \mathrm{mM} \mathrm{NaChol-Cys-PEG} 4$ or $0.2 \mathrm{mM}$ NaChol-Cys-PEG 23 ) of the amphiphile was taken and added in multiple stages to $\mathrm{pH} 7.0$ buffer kept in the calorimeter cell of capacity $200 \mu \mathrm{L}$ under constant stirring conditions, and the thermogram of the heats of stepwise dilution of the surfactant solution were recorded. The stirring speed was fixed at $400 \mathrm{rpm}$ and pH 7.0 buffer was taken in the reference cell. Each run was duplicated to check reproducibility. Enthalpy calculations were performed with the help of ITC software provided by the manufacturer. All measurements were carried out at $25{ }^{\circ} \mathrm{C}$. The $\Delta_{\mathrm{m}} \mathrm{H}^{\mathrm{o}}$ value was obtained by subtracting the initial enthalpy from the final enthalpy as indicated by the vertical arrow in each plot of Figure S6. The $\Delta_{\mathrm{m}} \mathrm{G}^{\mathrm{o}}$ value was calculated from the measured cmc value using the relationship:[6]

$$
\Delta_{\mathrm{m}} \mathrm{G}^{\mathrm{o}}=(1+\beta) R \mathrm{~T} \ln (\mathrm{c} a c)
$$

where $\beta$ is the degree of counterion binding of the surfactant molecule which is usually taken as 0.8 for anionic surfactants [7] and cac is the critical aggregation concentration of the amphiphile. The $\Delta_{\mathrm{m}} \mathrm{S}^{\mathrm{o}}$ value was evaluated by the Gibbs equation:

$$
\Delta_{\mathrm{m}} \mathrm{S}^{\mathrm{o}}=\left(\Delta_{\mathrm{m}} \mathrm{H}^{\mathrm{o}}-\Delta_{\mathrm{m}} \mathrm{G}^{\mathrm{o}}\right) / \mathrm{T}
$$

\subsection{Dye entrapment studies.}

For the dye entrapment study, a known amount of NaChol-Cys-PEG 4 or NaChol-Cys$\mathrm{PEG}_{23}$ was dissolved in $1 \mathrm{~mL}$ of $20 \mu \mathrm{M} \mathrm{Cal}\left(\lambda_{\max }=465 \mathrm{~nm}\right)$ in methanol. The mixture was vortexed and dried slowly in a RB flask by using rotavapor to make a thin film. For complete evaporation of the solvent, the flask was kept overnight in desiccators. The film was then rehydrated with a small amount of buffer overnight. The rehydrated suspension was vortexed for $30 \mathrm{~min}$ followed 
by dilution with appropriate buffer to obtain $1 \mathrm{mM}$ vesicle dispersion. A $2 \mathrm{~mL}$ volume of the resulting solution was then loaded onto a column packed with a pre-equilibrated Sephadex G-75 (25 $\mathrm{cm}$ height and $1.2 \mathrm{~cm}$ diameter) and eluted with appropriate buffer. Vesicular suspensions eluted right after the void volume. The filtration was carried out until free unentrapped Cal was separated from the entrapped dye. The eluent was collected in $2 \mathrm{~mL}$ fraction each.

The $\mathrm{pH}$-triggered release of $\mathrm{DPH}$ (or Cal) dye was performed at $\mathrm{pH} 2.0$ by monitoring its steady-state fluorescence spectrum at different time intervals. The release was triggered by adding a pre-calculated amount of dilute $\mathrm{HCl}$ to a $2.5 \mathrm{~mL}$ volume of the dye entrapped vesicle dispersion equilibrated at $37{ }^{\circ} \mathrm{C}$. The $\%$ release of $\mathrm{DPH}$ was calculated from the relative fluorescence intensities at $430 \mathrm{~nm}$ using the value of $\left(1-\mathrm{F} / \mathrm{F}_{\mathrm{o}}\right) \times 100 \%$, where $\mathrm{F}$ and $\mathrm{F}_{\mathrm{o}}$ are the fluorescence intensities of DPH at any time $t$ and at the start of the experiment (in $\mathrm{pH} 7.4$ buffer), respectively.

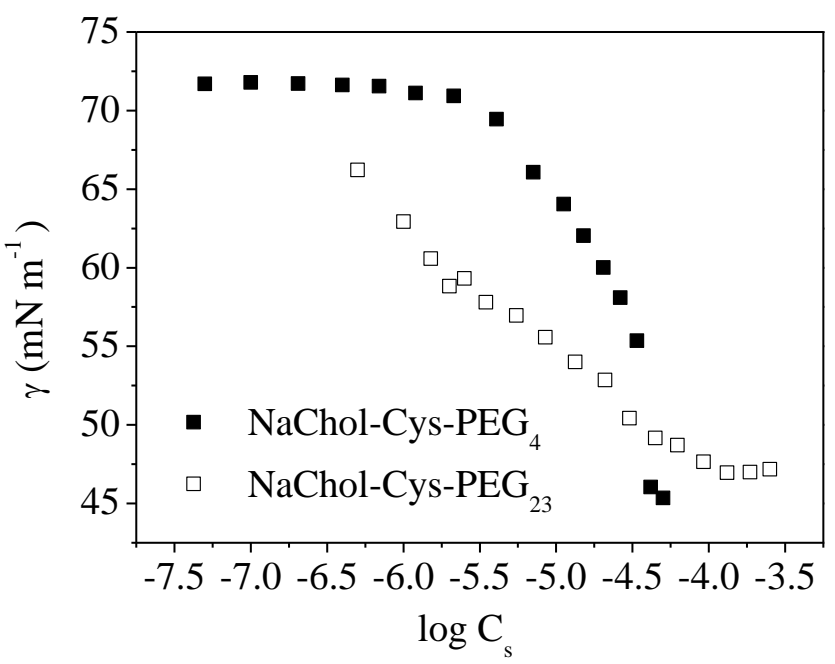

Figure S3. Plots showing variation of surface tension $\left(\gamma \mathrm{mN} \mathrm{m}^{-1}\right)$ of water with $\log \mathrm{C}_{\mathrm{s}}$ of NaChol-Cys-PEG 4 and NaChol-Cys-PEG 23 in $\mathrm{pH} 7.0$ buffer at $25^{\circ} \mathrm{C}$. 


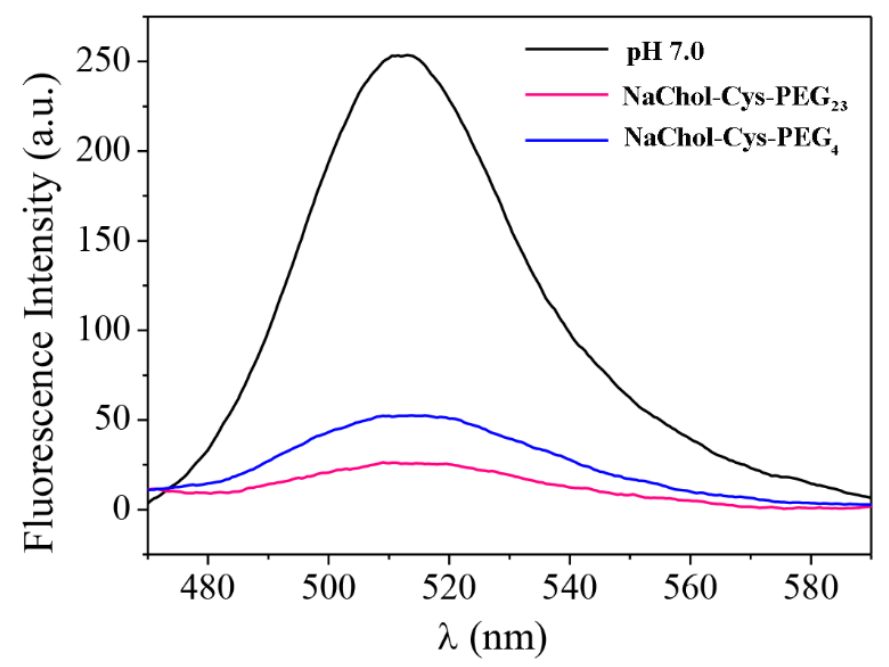

Figure S4 (a) Fluorescence spectra of Cal dye in phosphate buffer (pH 7.0) in the absence and presence of $(1 \mathrm{mM}) \mathrm{NaChol-Cys-PEG} 4$ and $\mathrm{NaChol-Cys-PEG}_{23}$ at $25^{\circ} \mathrm{C}$.

Table S1 The $\zeta$-potential values of vesicles at different concentrations of NaChol-Cys-PEG 4 and NaChol-Cys-PEG 23 in pH 7.0 and 3.0 buffers at $25^{\circ} \mathrm{C}$.

\begin{tabular}{cccc}
\hline \multirow{2}{*}{ Surfactant } & $\mathrm{C}_{\mathrm{s}}(\mathrm{mM})$ & \multicolumn{2}{c}{$\zeta$-potential $(\mathrm{mV})$} \\
& & $\mathrm{pH} \mathrm{7.0}$ & $\mathrm{pH} \mathrm{3.0}$ \\
\hline NaChol-Cys-PEG 4 & 0.01 & -13.8 & - \\
& 0.1 & -9.3 & -0.9 \\
NaChol-Cys-PEG 23 & 0.01 & -18.2 & - \\
& 0.1 & -13.5 & -1.3 \\
\hline
\end{tabular}



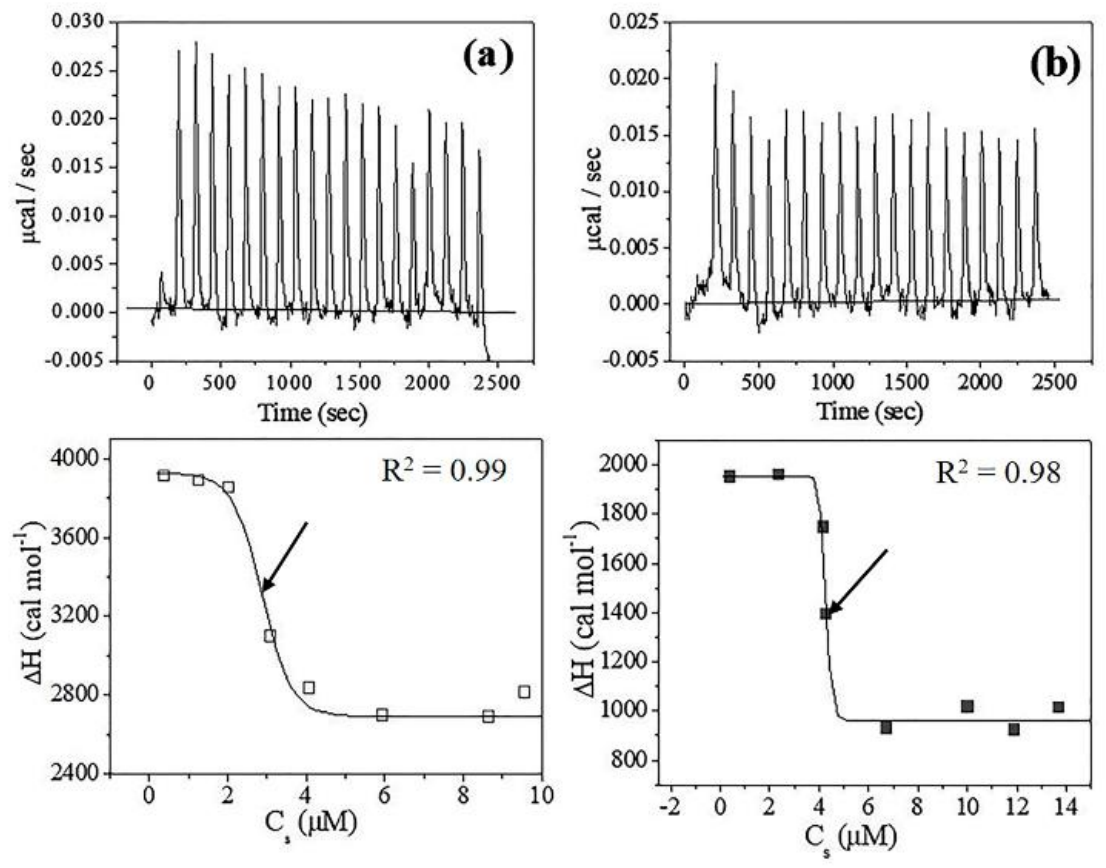

Figure S5 ITC thermograms (upper panel) and titration curves (corresponding lower panel) of

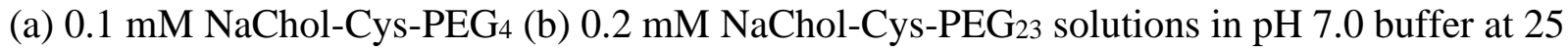
${ }^{\circ} \mathrm{C}$.

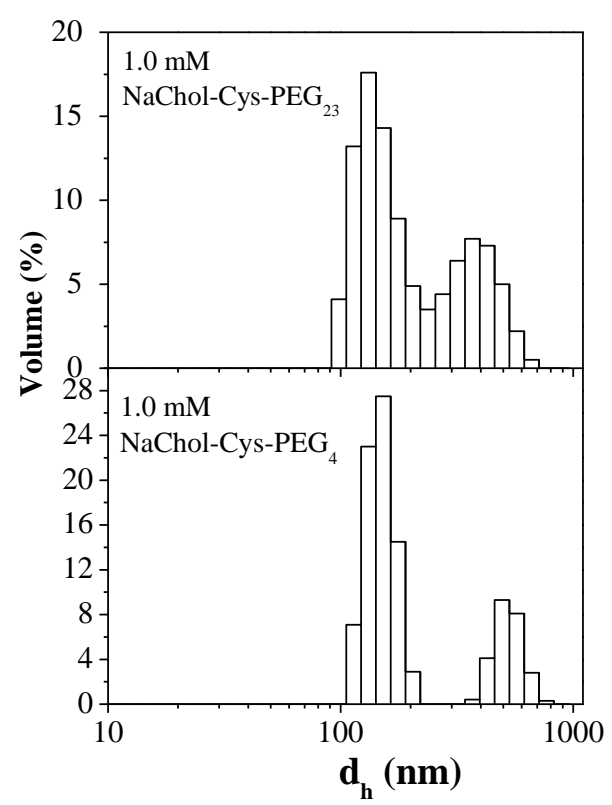

Figure S6 Size distribution profiles of the aggregates formed by $1.0 \mathrm{mM} \mathrm{NaChol-Cys-PEG} 4$ and NaChol-Cys-PEG23 in pH 3.0 buffer at $37^{\circ} \mathrm{C}$. 
Table S2. Fluorescence anisotropy $(r)$ and fluorescence lifetime $\left(\tau_{\mathrm{f}}\right)$ of DPH, microviscosity $\left(\eta_{\mathrm{m}}\right)$, and $\mathrm{I}_{1} / \mathrm{I}_{3}$ ratio in phosphate buffer containing 1.0 M NaChol-Cys-PEG 4 and NaChol-Cys$\mathrm{PEG}_{23}$ at $25^{\circ} \mathrm{C}$.

\begin{tabular}{|c|c|c|c|c|}
\hline \multirow[t]{2}{*}{ Amphiphile } & \multicolumn{3}{|c|}{ pH 7.0 } & pH 3.0 \\
\hline & $r$ & $\tau \mathrm{f}(\mathrm{ns}$ & $\eta_{\mathrm{m}}(\mathrm{mPa} \mathrm{s})$ & $\mathrm{I}_{1} / \mathrm{I}_{3}$ \\
\hline NaChol- Cys-PEG 4 & $\begin{array}{l}0.32 \pm \\
0.02\end{array}$ & 8.52 & $540( \pm 20)$ & $0.85 \pm 0.02$ \\
\hline NaChol- Cys-PEG 23 & $\begin{array}{l}0.29 \pm \\
0.02\end{array}$ & 7.45 & $485( \pm 30)$ & $0.91 \pm 0.03$ \\
\hline
\end{tabular}

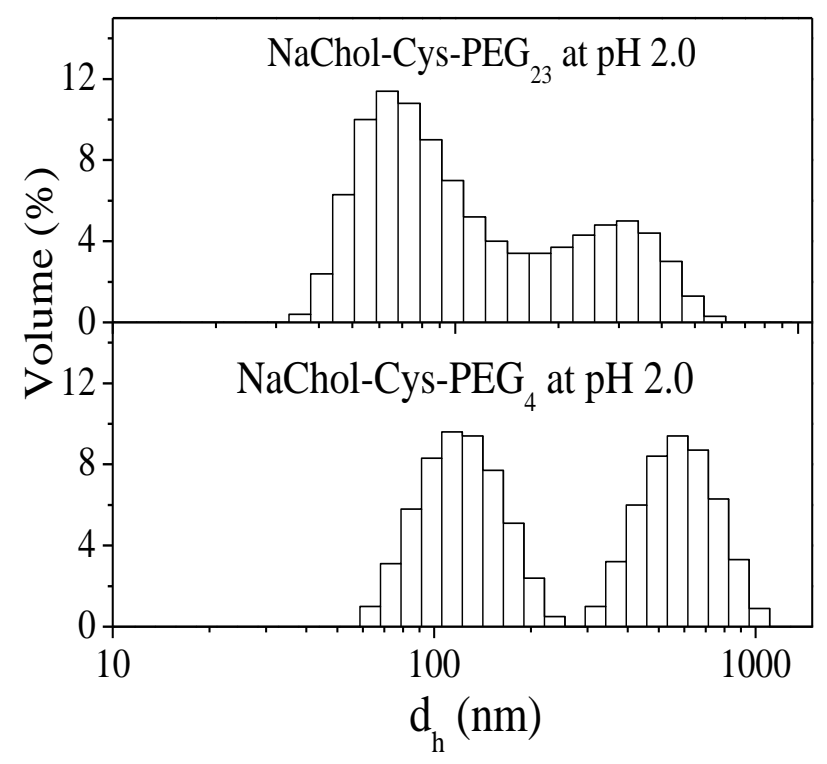

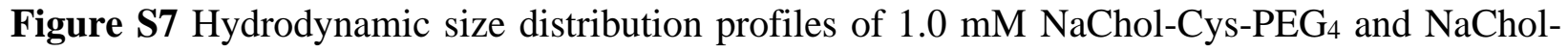
Cys-PEG 23 solution at $\mathrm{pH} 2.0$ after $3 \mathrm{~h}$ of incubation at $37^{\circ} \mathrm{C}$. 


\section{References}

(1) Ghosh, R.; Dey, J. Vesicle-to-Micelle Transition in Aqueous Solutions of 1-Cysteine-Derived Carboxylate Surfactants Containing Both Hydrocarbon and Poly(ethylene glycol) Tails.

Langmuir 2017, 332, 543-552.

(2) Lakowicz, J. R. Principles of Fluorescence Spectroscopy; Plenum Press: New York, 1983; p 132.

(3) Roy, S.; Mohanty, A.; Dey, J. Microviscosity of Bilayer membranes of some N-Acylamino Acid Surfactants Determined by Fluorescence Probe Method. Chem. Phys. Lett. 2005, 414, 2327.

(4) Debye, P. Polar Molecules; Dover: New York, 1929.

(5) Roy, S.; Mohanty, A.; Dey, J. Microviscosity of Bilayer Membranes of Some N-Acylamino Acid Surfactants Determined by Fluorescence Probe Method. Chem. Phys. Lett. 2005, 414, $23-27$.

(6) Verrall, R. E.; Milioto, S.; Zana, R. Ternary Water-in-Oil Microemulsions Consisting of Cationic Surfactants and Aromatic Solvents. J. Phys. Chem. 1988, 92, 3939-3943.

(7) Majhi, P. R.; Moulik, S. P. Energetics of Micellization: Reassessment by a High-Sensitivity Titration Microcalorimeter. Langmuir 1998, 14, 3986-3990. 